\title{
Sustainable Development Governance from Margins to Mainstream: Overcoming Traps by Embracing Complexity
}

\author{
Dr. Edoardo Monaco*
}

\begin{abstract}
:
The present essay reflects on the significances of a major turning point in global sustainable development governance: the adoption by the United Nations of the "2030 Agenda for Sustainable Development". The Agenda and its seventeen "Sustainable Development Goals" (SDGs) authoritatively redefine the very concept of development, as holistic synthesis of long-term achievements in the interconnected domains of society, politics, economics and environment. As a consequence, new, comprehensive metrics - quantitative and qualitative in nature - are required, so as to measure the pursuit of this new, complex form progress. While it appears important to overcome approaches that aim exclusively at unconditional market output maximization, economic growth remains, at this point, central to any development design. Yet, qualitative considerations about growth are, in a sustainable framework, now in order more than ever: in particular, factors such as diversity of productive know-how and economic inclusion matter greatly, as the observation of global development patterns over time demonstrates. Fundamentally, the 2030 Agenda calls for a paradigmatic shift investing all components of society - from citizens to governments, corporations, academics, media - and possibly challenges the very nature and content of the traditional social contracts that govern them.
\end{abstract}

Keywords: sustainable development; 2030 Agenda; SDG; complexity; quality; diversity.

\section{Redefining "development"}

By ambitiously committing, in September 2015, to the United Nations' "2030 Agenda for Sustainable Development" (hereinafter "2030 Agenda") and the related "Sustainable Development Goals" (hereinafter "SDGs"), the international community has finally agreed on a common general direction - in itself a very rare occurrence - that de facto acknowledges the extraordinary complexity and interdependence of modern development challenges.

Besides aiming at providing continuity to the 2000-2015 Millennium Development Goals agenda and its (patchy) success patterns ${ }^{1}$, the SDG agenda does, in essence, redefine on a global governance scale the very concept of development, which now comes "officially" to signify a more holistic pursuit of multidimensional societal wellbeing.

In this sense, this new definition transcends the more traditional, mainstream, simplistic interpretation of development as mere "economic growth", as well as the immediate "here and now" dimension that we got used to. "Sustainability" can in fact be interpreted

1 United Nations Statistics Division (UNSTAT), Department of Economic and Social Affairs, https://mdgs.un.org/unsd/mdg/default.aspx accessed in March 2017. 
as a phenomenon of "spatial and temporal interdependence": economic, social, political and environmental spheres can't be conceived as apart from each other, but are instead closely intertwined, complementary, even functional to each other. Similarly, immediate results can't be achieved at the expense of future generations, or regardless of consequences and costs that could manifest themselves in distant times or places (Sachs, 2015).

This represents an overall paradigmatic shift that is somewhat uncommon to the established "mainstream", but not completely new to the "margins" of the development governance debate and practice. Various small or medium scale projects - such as the numerous United Nations' Partnerships for Sustainable Development ${ }^{2}$ - have tried to implement similar "changes of perspectives" prior to the adoption of the overarching 2030 Agenda.

In the Kingdom of Bhutan - a country that actually prides itself on being considered at the "margins" of the world and its popular culture - sustainability has been the cornerstone of national development policymaking for decades: this tiny Himalayan kingdom has in fact conceived a holistic development strategy known as Gross National Happiness (GNH) which pursues broader wellbeing as a product of sustainable, equitable and balanced achievements across several connected domains - namely economic, political, environmental and social ones - and thus advocates the overcoming of common, domestic-product-centered paradigms. GNH started off as a generic idea of a very young king in the 1970s, but, in a distinctively "top-to-bottom" approach, it was later developed into a constitutionally relevant, overarching principle now informing every aspect of policymaking: today, a specific Commission - the GNH Commission operates in the country as a quasi-executive body that verifies policy proposals' compliance with GNH principles. Moreover, in order to identify policy targets and measure policy outcomes, an index - the GNH Index - has been developed on the basis of the Alkire-Foster Methodology (Alkire, Foster, 2011), also at the core of the Multidimensional Poverty Index developed at the Oxford University's Poverty and Human Development Initiative (OPHI) and now included in regular Human Development Reports (UNDP, HDR 2016).

One might argue that Bhutan's holistic development approach was favored by the country's primordial stage of development, by its small size, by the widespread Tantric Buddhist beliefs pervading popular culture and emphasizing harmonious interconnectedness and equal dignity of all universal components, and by a form of government - an absolute monarchy turned constitutional only in 2008 - in which topto-bottom governance designs could swiftly be implemented. Still, the adopted SDGs now seem to recognize the need for a very similar approach - a "sustainable development" approach as opposed to the "business as usual" one (Sachs, 2015)- to be adopted far beyond the Himalayan valleys of Bhutan, at a possibly global level.

2 United Nations' Sustainable Development Knowledge Platform, Partnerships for SDGs, https://sustainabledevelopment.un.org/partnerships/. 


\section{Quantity vs. Quality}

The sustainable development agenda calls for complex multidimensional solutions to the complex, multidimensional challenges of modern times, spanning across various domains, time frames, areas of competence, forms of government and even electoral mandates.

The intended approach, in other words, promotes the shift from merely quantitative evaluations of development to more comprehensive, relevant, qualitative evaluations of the same.

This new definition of development thus sets new ultimate goals, and consequently calls for the setting of new metrics, new ways to measure both achievements and, more importantly, shortcomings, so as to inspire policies, and evaluate as objectively as possible their results.

Metrics matter not just because they are fundamental tools to measure what societies and policymakers pursue, but also because societies and policymakers often end up pursuing what is measured (or "measurable"), especially when metrics in question are perceived to be simple, appealing, bullet-proof indicators of overall success.

Here comes a very problematic issue: in the mainstream, pre-SDG view, the concept of development has come to substantially equate that of economic growth. The metric of choice for this kind of pursuit has so far been the Gross Domestic Product (GDP). Its use, from its conception in the interwar period onwards, has dominated the politicoeconomic debate, and conquered a prominent position in the popular perception of "progress". But this relatively easy to calculate, rather straightforward market output indicator was originally conceived as a mere public accounting tool: it is, by definition, only quantitative in nature, and thus it is unable to capture the complexity of the new sustainable development approach, or of anything non-economic, for that matter. To some extent, actually, the GDP metric fails to accurately calculate even some relevant economic activities: it is in fact blind to unpaid work, leisure, use and depletion of environmental assets, subsistence activities. In other words, it counts only the "visible" money that is spent, but does not evaluate what money is spent for or anything that can't be easily quantified (Stiglitz et al., 2011).

Certainly, the shift towards fully qualitative evaluations of "wellbeing" or even subjective happiness, despite being technically possible - especially when it comes to qualitative aspects of wellbeing that have more evaluative than emotional components - may be culturally and politically challenging, in the short-term. Nevertheless we can, right away, consistently turn our attention towards existing solid measures that, just like the GDP, are quantitative in nature, yet significantly more comprehensive too. Methodologies like those at the core of the Human Development Index also deliver, for instance, singlenumber, aggregate figures and rankings that are as practical and easily comparable as the GDP, but far more wide-ranging, taking into consideration economic performance as well as achievements in health and education, which represent crucial components of sustainable societal progress.

Make no mistake, though: economic prosperity is still central, even in a multidimensional, sustainable development design. But economic growth in this context 
can no longer be considered as detached from other dimensions: it has to be mindful of, and even conducive to achievements in other dimensions.

That requires, again, qualitative analysis of economic performance, as far as its drivers are concerned, its potential to last over time, its ability to translate economic success into, for instance, poverty reduction and social inclusion, as well as optimal environmental management, or fair and effective governance.

\section{Economic growth, diversity and inclusion}

By looking at patterns and drivers of global economic growth in a historical perspective from the first industrial revolution onwards (Sachs, 2015), it appears evident that key to development is embracing and managing complexity by enhancing economic diversity and overall productive capacity (Hausmann et al., 2014).

Therefore, managing agriculture sustainably - from land tenure to productivity - is certainly important to prevent issues like food insecurity, environmental degradation and massive urbanization. But it's the additional development of dynamic industry and service sectors driven by technology and know-how (either endogenous or imported) that can create the complex value chains which offer the best opportunities to escape poverty and disenfranchisement. Diversification is key to sustained economic development, especially for transitional economies that are still largely dependent on the export of untransformed commodities. The ultimate goal for them should be the expansion of their society's "collective productive capability" (Hausmann et al., 2014): this requires even minimal, but consistent investments in human capital, to spread relevant know-how and productive capacity across communities in the most diverse and pervasive way possible - not just through formal teaching but, even more importantly, through direct emulation, observation, involvement. And this obviously implies that a certain level of openness of market-oriented economies to external inputs, exchange, investment and even migration, is indeed highly desirable. The reactionary call to "build walls" and reintroduce protectionist barriers to integration by a growing new wave of populist leaders, isn't good news for world development, which historically spiked when complexity, know-how and opportunities were pursued and spread on a large scale.

The last three decades of intense neo-liberalist, post-ISI ${ }^{3}$, global economic convergence have indeed delivered a significant reduction in the overall poverty headcount. But it can't be forgotten that East Asia, and in particular China alone, are largely responsible for these overall achievements. Many areas of the world, especially in Sub-Saharan Africa and South Asia remain trapped by factors like mere physical geography, natural resource mismanagement, conflict or uncontrolled demographic expansion. Nevertheless, hope is there too in the form of economic growth, and even more so where growth is marked by at least some factors of abovementioned "complexity" or "diversity".

Rwanda is an example of small East African nation of about 12 million people with extremely restive neighbors that only 20 years ago was on the brink of collapse due to a genocide that killed large portions (up to one million, mostly Tutsi) of its overall

3 The protectionist "Import Substitution Industrialization" adopted in least developed countries across the world between the 1950 s and the 1980 s. 
population. Despite that, the local government was recently able to put in place reforms of land tenure and agricultural productivity to support the shift from subsistence to commercial agriculture across its large rural population. Being already a landlocked country, then, policies have tried to avoid the additional "e-locked" or "air-locked" status (Collier, 2008), by placing great emphasis on the expansion of ICT infrastructure and service sectors like tourism and air travel, as well as on women's empowerment. Although human rights and political participation are a concern and thus a further challenge in the pursuit of truly sustainable overall development, Rwanda is now establishing itself as a success story and a model for Africa and beyond.

Mauritius - another somewhat remote country in Sub-Saharan Africa, largely devoid of major natural resource endowment - is quickly emerging as a remarkable example of ongoing, effective transition from agriculture into manufacturing, of market openness with its dynamic "Export Processing Zones" - as well as of human development (Frankel, 2016, Zafar, 2011). Botswana, too, has set a unique benchmark in terms of good governance and "adding value" to natural resources - in this case, diamonds before they are exported, thus keeping within the country crucial stages of the resource transformation value chain (Lewin, 2011), which can produce jobs and expertise. In South Asia, India itself now seems now to be able to make use of its remarkable collective know-how and is expected to be the fastest-growing major economy up until 2024 (CID, 2017), after years of intense growth hampered by outpacing demographic expansion, "red tape", limited investment in infrastructure and manufacturing, as well as inequality.

Growth per se is therefore not enough in a sustainable development context. It's the quality of growth that matters, but besides its "complexity", it's important how growth affects other dimensions of development too, such as, for instance, poverty and inequality. These are socio-economic phenomena that are indeed driven by income, but can't be exclusively defined by that. They too are in fact multidimensional, as they concern broader issues of "opportunity", like access to basic health care, education, proper nutrition, or housing. How, then, do we make sense of their complexity, attempt to analyze policy outcomes or inspire further policymaking? Once again, indicators come in handy: we have in fact measures that traditionally focus on quantitative, single financial aspects - such as poverty lines, Gini coefficient, income distribution ratios that are all extremely useful analytical tools, provided that they are used in combination with each other, and not exclusively. But we also can increasingly refer to comprehensive indicators such as like the Human Development Index (HDI) or the Multidimensional Poverty Index (MPI), that synthesize in single, aggregate, practical measures very wide ranging socio-economic development considerations. The MPI, for instance, can be easily broken down to deliver important information on relevant components of poverty defined as deprivation in education, health and household standards, not as mere "insufficient income" (Alkire, 2008; Alkire, Foster 2011) 4 . The richness of MPI data

4 The Multidimensional Poverty Index redefines poverty as weighed average deprivation across ten indicators: i.e. years of schooling, school attendance, child mortality, nutrition, cooking fuel, sanitation, drinking water, electricity, flooring, asset ownership within the same three domains of the Human Development Index, i.e. education, health and living standards - See http://www.ophi.org.uk/. 
compared to mere income poverty data - just like the HDI compared to the GDP epitomizes the very significance of multidimensional versus one-dimensional measurements ${ }^{5}$.

\section{Conclusion}

The 2030 Agenda has officially acknowledged development as a complex, multifaceted pursuit. Evaluative approaches have to be adapted accordingly: we have to consistently implement new metrics to measure and evaluate a new ultimate societal goal. No "one" indicator can alone capture all trends, especially if limited to financial output or income alone. It is encouraging, in this sense, to notice that the "conceptual revolution" of the 2030 Agenda comes alongside a "data revolution", consisting of a monitoring, follow-up and review system comprising of a number of indicators attached to every single $\mathrm{SDG}^{6}$ and adopted after months of consultations involving UN agencies, international organizations, national statistical offices, civil society organizations, academics and businesses.

Possibly, though, the Agenda calls for an even more fundamental "mindset revolution": civil society as a whole, at both local and global levels, has to acquire a "holistic mindset". This cultural shift requires time, especially if it occurs from the "bottom to the top" (top-to-bottom change is perhaps more immediate, but also more volatile as it often depends on charismatic personalities and changing circumstances).

It's a paradigmatic shift that may affect the very nature of the "social contract" as we know it, across all interdependent components of society, ultimately further enhancing the recognition and relevance of sustainable development. Civil society should fundamentally change the way it looks at progress, as well as, consequently, the expectations and evaluation parameters it has for its leaders. Policymakers - at national and transnational levels - should be responsible, capable and brave enough to take on challenges for which they can't easily claim credit, because sustainable results aren't as immediate, tangible, or convenient, as "business as usual" ones. Academia - through research, innovation, training, and incubation - has to provide the very scientific, theoretical and analytical tools - such as the very indicators mentioned above - to turn goals into reality, and accurately evaluate both achievements and shortcomings. The media - often enjoying an outreach that academics can only dream of - also have to play their part in making these changes more pervasive and "mainstream". Finally, the world of private corporations has to work in partnership with the others, by embracing the challenges of research, development and diffusion of their positive outputs, mindful of

5 In the case of India, the mere observation of economic growth trends could be narrow and misleading: average GDP growth in the period 2003-2013 was about 7\%; at the same time, though, income poverty headcount ratio in 2011 stood at 21.3\%; in the same year, multidimensional poverty, instead, was $53.8 \%$ and human development 0.547 , ranking $134^{\text {th }}$, only one position higher than in 2006 . Combining a comprehensive set of data concerning various aspects of socio-economic development - not to mention environment or governance - is essential to deliver a more meaningful overall analysis - See http://www.ophi.org.uk/ and UNDP HDR 2011-2016 http://hdr.undp.org/en.

6 United Nations Statistics Division (UNSTAT), Department of Economic and Social Affairs, https://unstats.un.org/sdgs/indicators/database/. 
the broad social and environmental responsibilities that come with playing a key role in modern society.

Of course, this mindset revolution will face strong forces of resistance and even disruption, such as growing waves populism (particularly in democratic contexts), traditional shortsighted, one-dimensional views, profit-maximizing outlooks, "ownbackyard" perspectives.

In general, the very adoption of the SDG agenda is reason for optimism. It's ambitious, perhaps too ambitious, and also hardly enforceable by the very institutions that have promoted it. Nevertheless, it is remarkable because it finally acknowledges - at the highest levels of global development governance - the complex interdependence of the challenges facing humanity, and at the same time streamlines the components of the approach needed to solve them. This is the kind of general direction and inspiration for intellectual debate that is necessary to bring about the complex change the world desperately needs.

\section{References}

Alkire, Comim, Qizilbash, The capability approach: concepts, measures and applications, Cambridge University Press, 2008;

Alkire, Foster, Counting and multidimensional poverty measurement, Journal of Public Economics, Elsevier. 95 (78): 476-487, August 2011;

Alkire, Wangdi, Zangmo, An extensive analysis of GNH index. Thimphu, Bhutan: Centre for Bhutan Studies, 2012;

Center for International Development (CID), Harvard University, Cambridge, USA http://atlas.cid.harvard.edu// and http://atlas.cid.harvard.edu/rankings/growth-predictions/ accessed in February 2017;

Hausmann, Hidalgo, Coscia, Bustos, Simoe, Yildrim, The Atlas of Economic Complexity: Mapping Paths to Prosperity, MIT Press, Cambridge, 2014;

Hausmann, Rigobon, An Alternative Interpretation of the Resource Curse: Theory and Policy Implications, Working Paper no. 9424, National Bureau of Economic Research, Cambridge, MA, 2003;

Hausmann, Rodrik, Economic Development as Self-Discovery, Working Paper No. 8952, National Bureau of Economic Research, Cambridge, 2002;

Hausmann, The Real Wealth of Raw Materials, Social Europe, 2014;

Frankel, Mauritius: African Success Story, in Edwards, Johnson, Weil, African Successes. Vol. 4, Chicago: University of Chicago Press, 2016;

Lewin, Botswana's Success: Good Governance, Good Policies, and Good Luck, in Chuhan-Pole, Angwafo, Yes Africa Can, Success Stories from a Dynamic Continent, World Bank, Washington DC, 2011;

Monaco, Competing Demands and Sustainable Solutions in Bhutan: Notes on Gross National Happiness and its Measurements", Journal of Management and Development Studies, Vol. 27, August 2016;

Morisset, Bastos, Rojid, Facing Off a Man-Made Disaster: Global Financial Crisis and Policy Response in the Small Tropical Island of Mauritius, World Bank Note, Africa Region, Washington, DC, 2010;

Sachs, The Age of Sustainable Development, Columbia University Press, 2015;

Sernau, Global Problems: The Search for Equity, Peace, and Sustainability, 4/e, Pearson, 2017;

Stiglitz, Sen, Fitoussi, Commission on the Measurement of Economic Performance and Social Progress (France), Mismeasuring Our Lives, Why GDP doesn't add up, New Press, 2010;

United Nations, Global Sustainable Development Report 2016, https://sustainabledevelopment.un.org/globalsdreport/2016, accessed in March 2017;

United Nations Development Program (UNDP), Human Development Report (HDR) 2011-2016, http://hdr.undp.org/en, accessed in March 2017; 
United Nations Statistics Division (UNSTAT), Department of Economic and Social Affairs, https://mdgs.un.org/unsd/mdg/default.aspx and https://unstats.un.org/sdgs/indicators/database/ accessed in March 2017;

United Nations' Sustainable Development Knowledge Platform, Partnerships for SDGs, https://sustainabledevelopment.un.org/partnerships/ accessed in April 2017;

World Bank, World Development Indicators Database, Washington DC, USA http://data.worldbank.org/indicator accessed in April 2017;

Zafar, Mauritius: An Economic Success Story, in Chuhan-Pole, Angwafo, Yes Africa Can, Success Stories from a Dynamic Continent, World Bank, Washington DC, 2011. 